\title{
Radioiodine-labeled anti-epidermal growth factor receptor binding bovine serum albumin-polycaprolactone for targeting imaging of glioblastoma
}

\author{
CHENGXIA LI $^{1}$, JIAN TAN $^{1}$, JIN CHANG $^{2}$, WEI LI $^{1}$, ZHONGYUN LIU $^{2}$, NING LI $^{1}$ and YANHUI JI ${ }^{1}$ \\ ${ }^{1}$ Department of Nuclear Medicine, Tianjin Medical University General Hospital, Heping, Tianjin 300052; \\ ${ }^{2}$ Institute of Nanobiotechnology, School of Materials Science and Engineering, Tianjin Key Laboratory \\ of Composites and Functional Materials, Tianjin University, Tianjin 300072, P.R. China
}

Received March 7, 2017; Accepted August 2, 2017

DOI: 10.3892/or.2017.5937

\begin{abstract}
The aim of this study was to look for a new medicine in diagnosing and treating of glioblastoma. Radioiodine-labeled anti-epidermal growth factor receptor (EGFR) binding nanoparticles were constructed. In vitro cell-binding assays were confirmed by confocal microscopy and flow cytometry. Cell cytotoxicity assays were evaluated by MTT assay; radionuclide uptake assays were performed by $\gamma$-counter. Radioiodine-imaging studies were conducted using a xenograft nude mouse model in vivo. The results showed that EGFR significantly enhanced the uptake and accumulation of BSA-PCL in the experimental model of xenografts in nude mice, suggesting improved specific nanoparticle-based delivery. In conclusion, the data showed ${ }^{131} \mathrm{I}-\mathrm{EGFR}-\mathrm{BSA}-\mathrm{PCL}$ leading radioiodine therapy for $\mathrm{U} 251$ and $\mathrm{U} 87$ cells had a good effect in vitro and in vivo. Thus, ${ }^{131} \mathrm{I}$-EGFR-BSA-PCL may provide a new method for glioblastoma treatment.
\end{abstract}

\section{Introduction}

Glioblastoma, the most common primary brain tumor in adults, is rapidly fatal. The current standard of care for newly diagnosed glioblastoma is surgical resection to a feasible extent, followed by adjuvant radiotherapy $(1,2)$. Current therapeutic strategies against glioblastoma (GBM) have failed to prevent disease progression and recurrence effectively $(3,4)$. The part played by molecular imaging (MI) in the development of novel therapies has gained increasing attraction in recent years (5). The combination of anatomical (MRI or CT) with metabolic (PET or SPECT) imaging techniques might provide even more

Correspondence to: Dr Jian Tan, Department of Nuclear Medicine, Tianjin Medical University General Hospital, 154 Anshan Road, Heping, Tianjin 300052, P.R. China

E-mail: tanpost@163.com

Key words: nanoparticles, radioiodine therapy, epidermal growth factor receptor detailed information on response to drug treatment compared with single modality imaging $(5,6)$.

Epidermal growth factor receptor (EGFR) is a cell-surface receptor that plays a key role in signaling pathways regulating cell proliferation, angiogenesis, and tumor metastases $(7,8)$. EGFR is one of the four members of the EGFR family. EGFR is widely overexpressed in several tumor types including breast cancer, melanoma, and brain glioblastoma, making this receptor an attractive candidate for anticancer therapy $(7,9)$. EGFR is also an attractive drug target because it is widely expressed in many cancers and has well-documented oncogenic activities. Anticancer therapies targeting EGFR have been studied since the 1980s. To date, several antibodies and small-molecule inhibitors are directed against EGFR. These antibodies and inhibitors are actively being developed by biotechnology and pharmaceutical companies as cancer therapeutics, such as C225 (cetuximab), EMD 72000 (matuzumab), gefitinib, erlotinib, and lapatinib. EGFR expression level is related to disease development and prognosis $(10,11)$. Some studies showed that treatment of locoregionally advanced head and neck cancer with concomitant high-dose radiotherapy plus cetuximab improves locoregional control and reduces mortality without increasing the common toxic effects associated with radiotherapy to the head and neck (12). Traditional EGFR-targeted nanoparticle carriers play a role in the treatment of malignancy but do not provide direct guidance in the diagnosis and evaluation of the prognosis of malignant tumor.

In the current study, radioiodine-labeled anti-EGFR binding nanoparticles were constructed for treatment and imaging of glioblastoma in vitro and in vivo.

\section{Materials and methods}

Materials. Monoclonal anti-human EGFR antibody was obtained from Cetuximab, Merck KGaA, Germany. ${ }^{131}$ I was provided by the Beijing Atomic Gaoke Limited by Share Ltd. The nanoparticles were obtained from the Institute of Nanobiotechnology, School of Materials Science and Engineering, Tianjin Key Laboratory of Composites and Functional Materials, Tianjin University. 
Self-assembly of amphiphilic BSA-PCL conjugate; (9,13-15). The amphiphilic BSA-PCL conjugate was synthesized as previously described (16), and the nanosized self-assembly of the amphiphilic BSA-PCL conjugate was obtained via emulsion-solvent evaporation method. Briefly, $4 \mathrm{mg}$ of BSA-PCL conjugate was dissolved in $4 \mathrm{ml}$ of phosphate buffer ( $\mathrm{PB}, 0.1 \mathrm{M}, \mathrm{pH}$ 7.4) at room temperature and sonicated in a bath sonicator for $10 \mathrm{~min}$. During the ultrasonic treatment process, $2 \mathrm{ml}$ of dichloromethane was slowly injected into the PB via syringe. Dichloromethane was then evaporated with a vacuum rotary evaporator, and self-assembly of the cetuximab-decorated BSA-PCL conjugate was prepared with the same process. The obtained PB solutions of the self-assemblies of the BSA-PCL and cetuximab-decorated BSA-PCL conjugates were stored at $4^{\circ} \mathrm{C}$.

Cell culture. U251 and U87 human glioblastoma cells were purchased from Cell Resource Center, Institute of Basic Medical Sciences, Chinese Academy of Medical Sciences/Peking Union Medical College (Beijing, China). The U251 and U87 cells which overexpressed EGFR were cultured as a monolayer in DMEM media supplemented with $100 \mathrm{U} / \mathrm{ml}$ of penicillin, $100 \mathrm{M} / \mathrm{ml}$ streptomycin, and $10 \%$ FBS in a humidified atmosphere containing $5 \% \mathrm{CO}_{2}$ at $37^{\circ} \mathrm{C}$.

${ }^{131}$ I-labeling of nanoparticles; (17). We used the well-established direct labeling method for anti-EGFR-nanoparticles EGFR-BSA-PCL and BSA-PCL $(18,19)$. EGFR-BSA-PCL and BSA-PCL were labeled with ${ }^{131} \mathrm{I}$ (Beijing Atomic Hi-Tech Co., Ltd.) using chloramine-T method. The same amounts of EGFR-BSA-PCL or BSA-PCL were diluted in PB to a total volume of $100 \mu \mathrm{l}(1 \mathrm{mg} / \mathrm{ml})$, and $\sim 37 \mathrm{MBq}{ }^{131} \mathrm{I}$ was added. Up to $100 \mu \mathrm{l}$ of chloramine-T $(5 \mathrm{mg} / \mathrm{ml}$ in PB) was added. After $60 \mathrm{sec}$ of incubation, complete oscillation using an oscillator was simultaneously needed. The reaction was stopped by adding $100 \mu \mathrm{l}$ of sodium metabisulfite $(5 \mathrm{mg} / \mathrm{ml}$ in PB), and complete oscillation for $60 \mathrm{sec}$ was also needed. To separate the labeled EGFR-BSA-PCL or BSA-PCL from the low-molecularweight compounds, centrifugation method was adopted to remove the small molecules. Our group used a centrifuge tube (Amicon ${ }^{\circledR}$ Pro Purification System, Merck Millipore). The specific radioactivity was approximately 333 and $296 \mathrm{MBq} / \mathrm{mg}$ for EGFR-BSA-PCL and BSA-PCL, respectively. The ratio of radioiodine label was also calculated.

Confocal microscopy; $(10,15,20)$. As previously mentioned, cells were planted in the confocal small dish $\left(5 \times 10^{3}\right.$ cells/dish). Using the above steps, EGFR-BSA-PCL and BSA-PCL (marked with FITC) were added to each dish and incubated another 4 and $12 \mathrm{~h}$, respectively. After incubating the rejected nanoparticles, the cells were washed twice or thrice repeatedly with sterile PBS and fixed with $0.5 \mathrm{ml}$ of paraformaldehyde. Extracellular localization of fluorescent EGFR-labeled nanoparticles was then periodically visualized and recorded using Laser Scanning Confocal Microscope (Leica TCS SP2; Leica, Munich, Germany).

Flow cytometry; (21). Flow cytometry was used to evaluate the binding of EGFR-BSA-PCL and BSA-PCL to target cells (EGFR ${ }^{+}$: U251 and U87). U251 and U87 cells were seeded into a cell-culture flask $\left(5 \times 10^{6}\right.$ cells) and incubated for $24 \mathrm{~h}$. Up to $1 \mathrm{ml}$ each of EGFR-BSA-PCL and BSA-PCL $(1 \mathrm{mg} / \mathrm{ml}$, marked with FITC) was added, and the cells were incubated for 4 or $12 \mathrm{~h}$. After incubation, the supernatant was discarded, and the plates were washed two to four times in PBS and then used for trypsinization. After centrifugation, $250 \mu \mathrm{l}$ of the cell suspension was obtained, and another $250 \mu \mathrm{l}$ of paraformaldehyde was added. The cells were then analyzed by a BD FACSCalibur flow cytometry (BD Biosciences, Franklin Lakes, NJ, USA) using $490 \mathrm{~nm}$ laser source.

MTT cytotoxicity assay; $(20,22)$. MTT assays were conducted to evaluate the cytotoxicity of ${ }^{131}$ I-labeled EGFR-BSA-PCL and BSA-PCL. U251 and U87 cells were seeded into 96-well microplates with $1 \times 10^{4}$ cells/well. The ${ }^{131}$ I-EGFR-BSA-PCL, ${ }^{131}$ I-BSA-PCL, EGFR-BSA-PCL, or BSA-PCL under different concentration gradients were added and then incubated for another $4 \mathrm{~h}$. After removing all the nanoparticles, $20 \mu \mathrm{l}$ of MTT reagent [3-(4,5 dimethylthiazol-2-yl)-2,5-diphenyl tetrazolium bromide; Sigma] was added $(5 \mathrm{mg} / \mathrm{ml})$ into each well. The plates were incubated for $4 \mathrm{~h}$, and the MTT-containing medium was removed and replaced with DMSO. The amount of the blue formazan compound indicated the number of living cells and was determined using a spectrophotometer $(492 \mathrm{~nm})$. Finally, after gently shaking the microplates for $10 \mathrm{~min}$ to dissolve the formazan, each sample with six replicates $(\mathrm{n}=6)$ was analyzed on a BioTek ELX 800 microplate reader (BioTek Instruments, Inc., Winooski, VT, USA) at $\lambda=492 \mathrm{~nm}$.

Radionuclide uptake in vitro; $(23,24)$. Briefly, the cells $\left(10^{5} /\right.$ well) were plated in triplicates in 96 -well plates. Subsequently, 0.37-3.7 $\mathrm{MBq}{ }^{131}$ I-EGFR-BSA-PCL and ${ }^{131}$ I-BSA-PCL were added into each well for $4 \mathrm{~h}$. The medium was then completely removed, and the cells were quickly washed twice with ice-cold PBS. Up to $200 \mu 1$ of $10 \%$ FBS-DMEM was added into each well. A $\gamma$-counter (LKB Gamma 1261; LKB Instruments, Mt. Waverley, Australia) was used to calculate the counts per minute (CPM) after $24 \mathrm{~h}$.

Experimentation on animals; (25). This study was carried out in strict accordance with the recommendations in the Guide for the Care and Use of Laboratory Animals of the National Institutes of Health and China Regulations For the Administration of Affairs Concerning Experimental Animals. The protocol was approved by the Committee on the Ethics of Animal Experiments of the Tianjin Medical University General Hospital. All surgery was performed under sodium pentobarbital anesthesia, and all efforts were made to minimize suffering.

Four-week-old BALB/c nude female mice were obtained from the PLA Military Academy of Medical Sciences Laboratory Animal Center. The mice were normally bred and maintained under specific-pathogen-free conditions with constant temperature and humidity range. The nude mice $(n=27)$ were inoculated with $\mathrm{U} 87$ in the subcutaneous tissue upper back. A total volume of $50 \mu 1$ was inoculated in the subcutaneous tissue upper back of the mice using a syringe. The U87 cells were slowly injected, and the syringe was kept in for 1-2 min before being retracted to avoid cells from ascending 
through the injection canal. Based on preliminary studies, the total span of the experiments was set to 21 days to ensure sufficient tumor development. However, the mice developed signs of considerable tumor burden, which is defined as loss of $>20 \%$ of the mice initial body weight, and the diameter of the tumor deposit was $>1 \mathrm{~cm}$. After 21 days, the animals were divided into three experimental groups with three mice each: groups $\mathrm{A}$, $\mathrm{B}$, and $\mathrm{C}$ were treated by intratumoral injection with $74 \mathrm{MBq}$ (370 MBq/ml) ${ }^{131} \mathrm{I}$-EGFR-BSA-PCL, $74 \mathrm{MBq}(370 \mathrm{MBq} / \mathrm{ml})$ ${ }^{131} \mathrm{I}-\mathrm{BSA}-\mathrm{PCL}$, and $74 \mathrm{MBq}(370 \mathrm{MBq} / \mathrm{ml}){ }^{131} \mathrm{I}$, respectively.

At 4,24 , and $72 \mathrm{~h}$ after intratumoral injection, singlephoton emission computed tomography (SPECT) (Discovery VH; GE Healthcare, Milwaukee, WI, USA) imaging was previously performed (26). To reduce the exposure of salivary and thyroid glands to unwanted radiation, all the mice were administered with $1 \%$ sodium perchlorate solution via their drinking water for $4 \mathrm{~h}$ before the experiment.

Statistical analysis. All experiments were performed in triplicate unless otherwise indicated. Statistical analysis was performed using SPSS software (SPSS 15.0). Results are presented as mean \pm SD. Statistical significance was examined using Student's t-test. $\mathrm{P}<0.05$ was considered statistically significant. For different experimental groups, we compared the difference between different drugs at the same medication time and at the same dose of the drug; for the same group comparison, we compared the efficacy of the same drug in different administration times, and compared the efficacy of the same medication time at different doses.

\section{Results}

Internalization of EGFR-BSA-PCL and BSA-PCL. Confocal microscopy was used to analyze the binding and internalization of targeted and non-targeted BSA-PCL. Specific fluorescence staining on U251 and U87 cells was shown upon incubation with EGFR-BSA-PCL and BSA-PCL after 4 or $12 \mathrm{~h}$ at $37^{\circ} \mathrm{C}$ (Fig. 1). The fluorescence intensity of the EGFR-BSA-PCL group was stronger than that of the BSA-PCL group in both U251 and U87 cells regardless of similar conditions at $37^{\circ} \mathrm{C}$ for 4 or $12 \mathrm{~h}$ of incubation.

Flow cytometry binding analyses of EGFR-BSA-PCL and $B S A-P C L$. The binding activity of the EGFR-BSA-PCL and BSA-PCL conjugates was further confirmed by flow cytometry using the U251 and U87 cells that express EGFR. FCM analyses revealed results consistent with those observed in the fluorescence microscopy analyses. Hence, the binding and uptake of EGFR-BSA-PCL were significantly higher than those of BSA-PCL in both the U87 and U251 cells after 4 or $12 \mathrm{~h}$ of incubation at $37^{\circ} \mathrm{C}$. The uptake of EGFR-BSA-PCL was 70.5 and $59.2 \%$ in the U251 and U87 cells, respectively, after $4 \mathrm{~h}$ of incubation. The uptake of EGFR-BSA-PCL was 76.0 and $60.0 \%$ in the U251 and U87 cells, respectively, after $12 \mathrm{~h}$ of incubation (Fig. 2). These findings implied that EGFR-BSA-PCL had special binding efficiency in the U251 and U87 cells which expressed EGFR.

Cellular binding and uptake of the two different ${ }^{131}$ I-labeled BSA-PCLs were evaluated by confocal fluorescence microscopy and flow cytometry in the U251
A
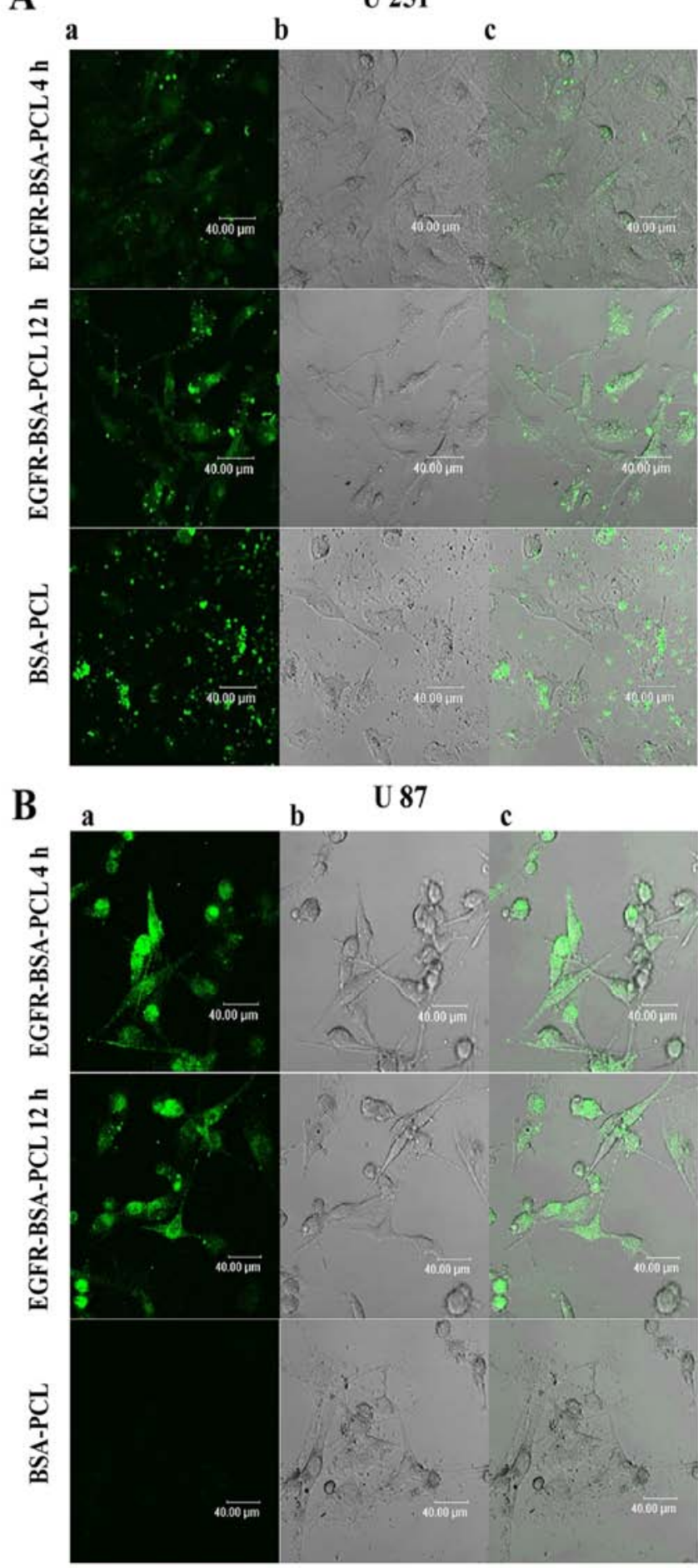

Figure 1. Binding activity of EGFR-BSA-PCL and BSA-PCL to target and control cells detected by FITC-labeled indirect confocal microscopy. (A) U251. (B) U87. a) Fusion images of light microscopy and fluorescence microscopy. b) Ordinary light microscope image. c) Fluorescence microscope image. Compared with BSA-PCL groups, more green fluorescence is observed on the surface and interior of cells in the EGFR-BSA-PCL group, indicating that the EGFR-BSA-PCL labeled with FITC is easier to connect to the cell surface and more easily swallowed into the cell; no significant differences were found in the EGFR-BSA-PCL group after 4 and $12 \mathrm{~h}$ for the green fluorescence of the surface and interior of the cells.

and U87 cell lines. The targeting efficiency of ${ }^{131}$ I-EGFRBSA-PCL was considerably higher than that of ${ }^{131} \mathrm{I}-\mathrm{BSA}-\mathrm{PCL}$, EGFR-BSA-PCL, or naked BSA-PCL in both U251 and 

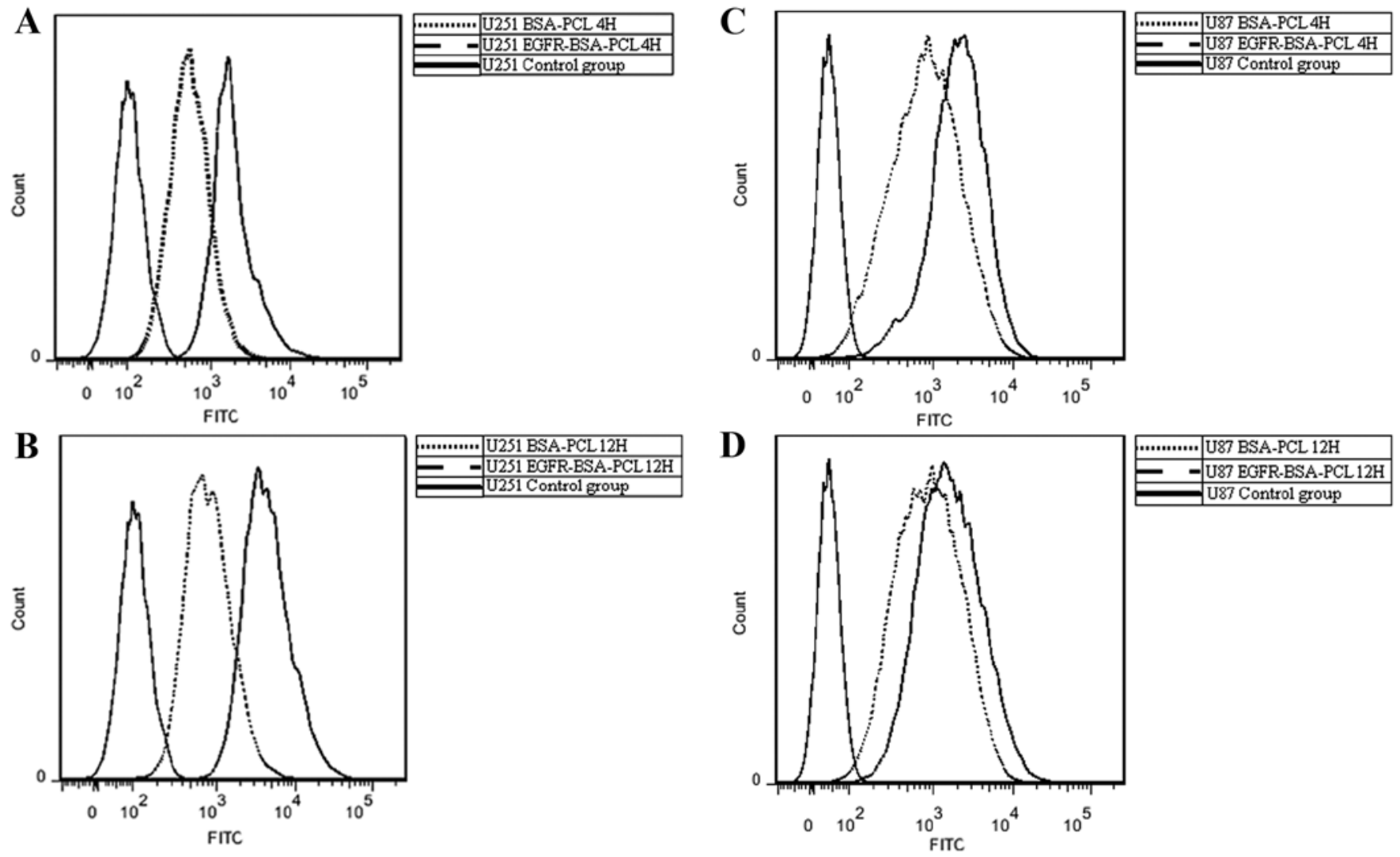

Figure 2. Flow cytometry analysis showing uptake of EGFR-BSA-PCL and BSA-PCL by U251 (A and B) and U87 (C and D) cells. U251 and U87 cells without nanoparticles as control; (A) U251 cells incubated with EGFR-BSA-PCL or BSA-PCL for $4 \mathrm{~h}$, showed 70.5 and $49.1 \%$, respectively. (B) U251 cells incubated with EGFR-BSA-PCL or BSA-PCL for $12 \mathrm{~h}$, showed 76.0 and 49.8\%, respectively. (C) U87 cells incubated with EGFR-BSA-PCL or BSA-PCL for $4 \mathrm{~h}$, showed 59.2 and $22.9 \%$, respectively. (D) U87 cells incubated with EGFR-BSA-PCL or BSA-PCL for 12 h, showed 60.0 and $51.2 \%$, respectively.

Table I. After incubated with nanoparticles $4 \mathrm{~h}$, the U251 and U87 cell viability in $96 \mathrm{~h}$.

\begin{tabular}{lccccc}
\hline & \multicolumn{2}{c}{ U251 } & & \multicolumn{2}{c}{ U87 } \\
\cline { 2 - 3 } \cline { 5 - 6 } Treatment & ${ }^{131}$ I-EGFR-BSA-PCL (\%) & ${ }^{131}$ I-BSA-PCL $(\%)$ & & ${ }^{131}$ I-EGFR-BSA-PCL (\%) & ${ }^{131}$ I-BSA-PCL (\%) \\
\hline $0.37 \mathrm{MBq}$ & $80.67 \pm 1.15$ & $65.67 \pm 1.16$ & & $44.67 \pm 1.53$ & $68.67 \pm 0.58$ \\
$0.925 \mathrm{MBq}$ & $41.67 \pm 4.73$ & $51.67 \pm 1.53$ & & $28.33 \pm 1.53$ & $48.00 \pm 1.00$ \\
$1.85 \mathrm{MBq}$ & $73.33 \pm 2.52$ & $71.00 \pm 2.65$ & & $32.33 \pm 2.08$ & $60.00 \pm 1.00$ \\
$2.775 \mathrm{MBq}$ & $75.00 \pm 5.00$ & $95.00 \pm 3.00$ & & $34.33 \pm 1.53$ & $62.67 \pm 0.58$ \\
$3.7 \mathrm{MBq}$ & $91.67 \pm 1.53$ & $95.33 \pm 2.52$ & & $50.33 \pm 0.58$ & $70.33 \pm 0.58$ \\
\hline
\end{tabular}

U87 cell lines.Analysis of cell viability determined by MTT cytotoxicity experiment; (7,27-29). Cytotoxicity was determined using MTT assay as previously reported. Time- and dose-dependent MTT studies were performed (Fig. 3, Table I). The data showed that $0.925 \mathrm{MBq}{ }^{131}$ I-EGFRBSA-PCL or ${ }^{131}$ I-BSA-PCL had the strongest inhibition effect on tumor cells at 24, 48,72 and $96 \mathrm{~h}$. Experiments also showed that ${ }^{131}$ I-EGFR-BSA-PCL had better tumor inhibition effect than ${ }^{131}$ I-BSA-PCL with extended time. After incubating the nanoparticles for $4 \mathrm{~h}$, the cell viability of the U251 and U87 cells was determined after 24, 48, 72 and $96 \mathrm{~h}$, respectively. The cells incubated with ${ }^{131} \mathrm{I}$ or cetuximab alone have no effect on the survival of glioma cells (data not shown).
Radioiodine uptake of ${ }^{131}$ I-labeled nanoparticles in vitro. Confocal microscopy, flow cytometry, and MTT analyses revealed that both ${ }^{131}$ I-EGFR-BSA-PCL and ${ }^{131}$ I-BSA-PCL could inhibit cell growth. However, the inhibition effect of ${ }^{131}$ I-EGFR-BSA-PCL was better than that of ${ }^{131}$ I-BSA-PCL in both U251 and U87 cells. Radionuclide uptake results were consistent with the CPM of ${ }^{131}$ I-EGFR-BSA-PCL, which was always higher than ${ }^{131}$ I-BSA-PCL in both U251 and U87 cells. After $4 \mathrm{~h}$ incubation with ${ }^{131}$ I-EGFR-BSA-PCL and ${ }^{131}$ I-BSA-PCL, the radioiodine uptake was distributed in a parabola fashion in the U251 and U87 cells (Fig. 4). When radioiodine uptake reached the peak, the CPM decreased as the dose of ${ }^{131}$ I-labeled nanoparticles increased. In the U251 cells, 

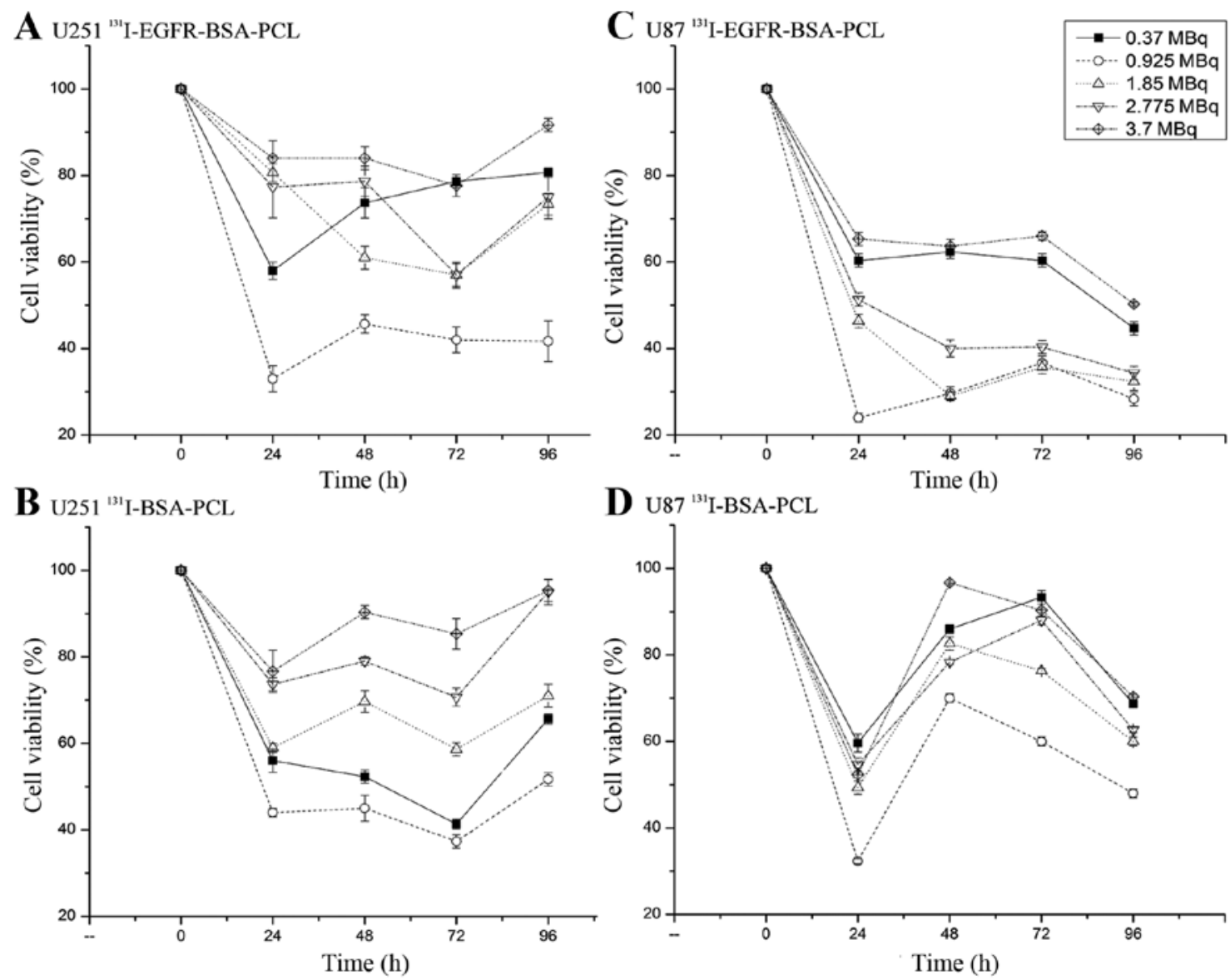

Figure 3. MTT assay performed for ${ }^{131}$ I-EGFR-BSA-PCL and ${ }^{131}$ I-BSA-PCL in both U251 and U87 cells. (A) U251 cell incubated in ${ }^{131}$ I-EGFR-BSA-PCL; (B) U251 cell incubated in ${ }^{131}$ I-BSA-PCL; (C) U87 cell incubated in ${ }^{131}$ I-EGFR-BSA-PCL; (D) U87 cell incubated in ${ }^{131}$ I-BSA-PCL. The observed IC ${ }_{50}$ for pure ${ }^{131}$ I-EGFR-BSA-PCL was $1.37 \mathrm{MBq}(6.85 \mathrm{MBq} / \mathrm{ml})$ and $1.62 \mathrm{MBq}(8.1 \mathrm{MBq} / \mathrm{ml})$ against U251 and U87 cells, respectively. The observed IC ${ }_{50}$ for pure ${ }^{131} \mathrm{I}$-BSA-PCL was $2.04 \mathrm{MBq}(10.2 \mathrm{MBq} / \mathrm{ml})$ and $2.38 \mathrm{MBq}(11.9 \mathrm{MBq} / \mathrm{ml})$ against $\mathrm{U} 251$ and $\mathrm{U} 87$ cells, respectively.
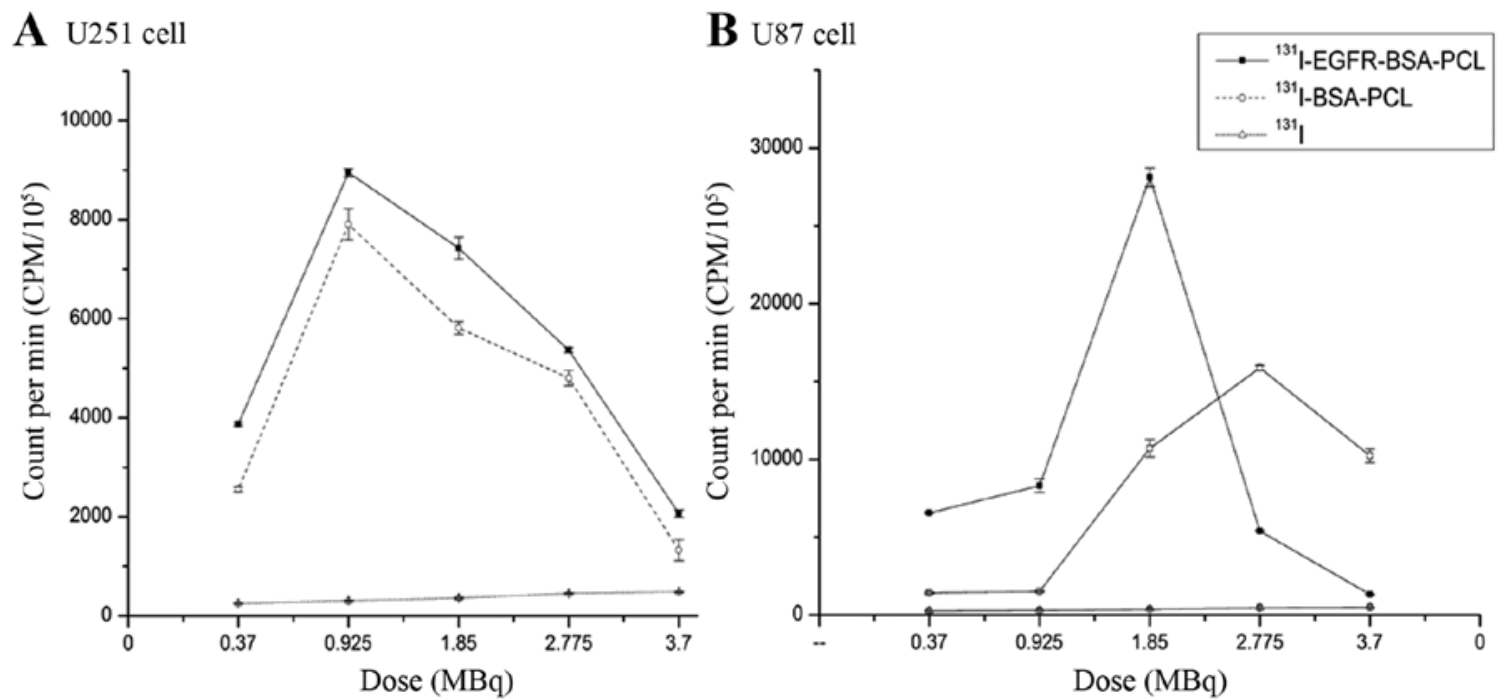

Figure 4. ${ }^{131}$ I, ${ }^{131}$ I-EGFR-BSA-PCL, and ${ }^{131}$ I-BSA-PCL uptake in U251 and U87 cells. (A) U251 cells and (B) U87 cells. Radioactivity count in EGFR-BSA-PCL group is much higher than that in BSA-PCL and ${ }^{131}$ I groups. In EGFR-BSA-PCL and BSA-PCL groups, with the increase of drug concentration, radioactivity count decreased as parabola-like changes decreased; in ${ }^{131} \mathrm{I}$ group the radioactivity count is kept at a low level and was linear.

$0.925 \mathrm{MBq}^{131} \mathrm{I}-\mathrm{EGFR}-\mathrm{BSA}-\mathrm{PCL}$ and $1.85 \mathrm{MBq}{ }^{131} \mathrm{I}-\mathrm{BSA}-\mathrm{PCL}$ had the highest CPM. In the U87 cells, $1.85 \mathrm{MBq}{ }^{131} \mathrm{I}$-EGFRBSA-PCL and $2.775 \mathrm{MBq}{ }^{131} \mathrm{I}-\mathrm{BSA}-\mathrm{PCL}$ had the highest CPM.
SPECT imaging: Biodistribution in animal experiments; $(17,21,22)$. The biodistribution of ${ }^{131}$ I-EGFR-BSA-PCL, ${ }^{131}$ I-BSA-PCL, and ${ }^{131} \mathrm{I}$ in mice bearing U87 tumor xenografts 


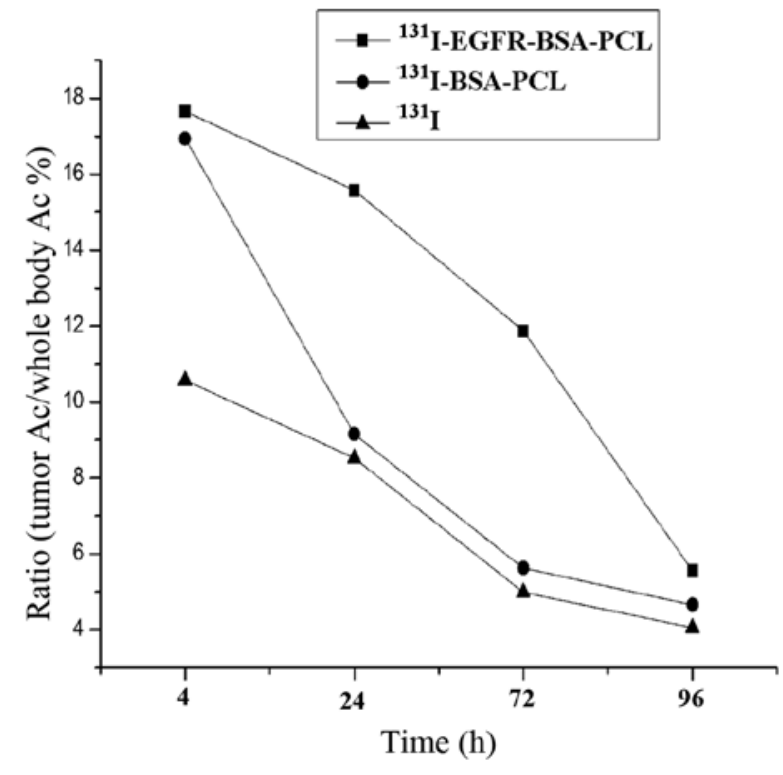

Figure 5. Ratio of radioactive counts at different time points. At $4 \mathrm{~h}$ after injection was the highest, followed by a decreasing trend; the ratio of radioactive counts at different time points in ${ }^{131}$ I-EGFR-BSA-PCL group was higher than that in ${ }^{131} \mathrm{I}$-BSA-PCL and ${ }^{131} \mathrm{I}$ groups, and the decreasing trend was slower, indicating that the residence time of ${ }^{131}$ I-EGFR-BSA-PCL in the tumor was the longest.

at 4,24 , and $72 \mathrm{~h}$ and the ratio of radioactivity counts at different time points are shown in Fig. 5.

SPECT images showed that after the injection of the drug, the development of the tumor site was the most clear (Fig. 6). This finding indicated that the drugs are mainly gathered at the tumor site, and with time, the development of the tumor tissues gradually fade; the other parts of the nude mice develop gradually, indicating that the drug entered through the bloodstream to other parts of the body and the retention time of ${ }^{131}$ I-EGFR-BSA-PCL in the tumor tissues was longer than that of ${ }^{131}$ I-BSA-PCL and ${ }^{131}$ I. The ratio of radioactivity count with tumor tissue and nude body at $4 \mathrm{~h}$ after injection was the highest, followed by a decreasing trend. In the ratio of radioactive counts at different time points, ${ }^{131}$ I-EGFR-BSA-PCL group was higher than the ${ }^{131}$ I-BSA-PCL and ${ }^{131}$ I groups, and the decreasing trend was slower, indicating that the residence time of ${ }^{131}$ I-EGFR-BSA-PCL in the tumor was the longest.

\section{Discussion}

EGFR overexpression or overactivation is commonly observed in GBM tumors $(40-70 \%$ of patients) $(30,31)$. EGFR overexpression has been correlated with treatment resistance, as well as poor survival and prognosis $(22,32)$. Given the advantage of this feature of EGFR, anti-EGFR was connected to the surface of nanoparticles, thereby targeting the combination of nanoparticles to the surface of glioma cells and simultaneously increasing the number of nanoparticles on the cell surface or with internal retention time. The use of the EGFR tyrosine kinase inhibitor cetuximab showed no measurable responses (33). In vitro studies revealed that EGFR-bound nanoparticles are easier to combine with the GMB cells, and the rate of combination was higher. Cell viability was

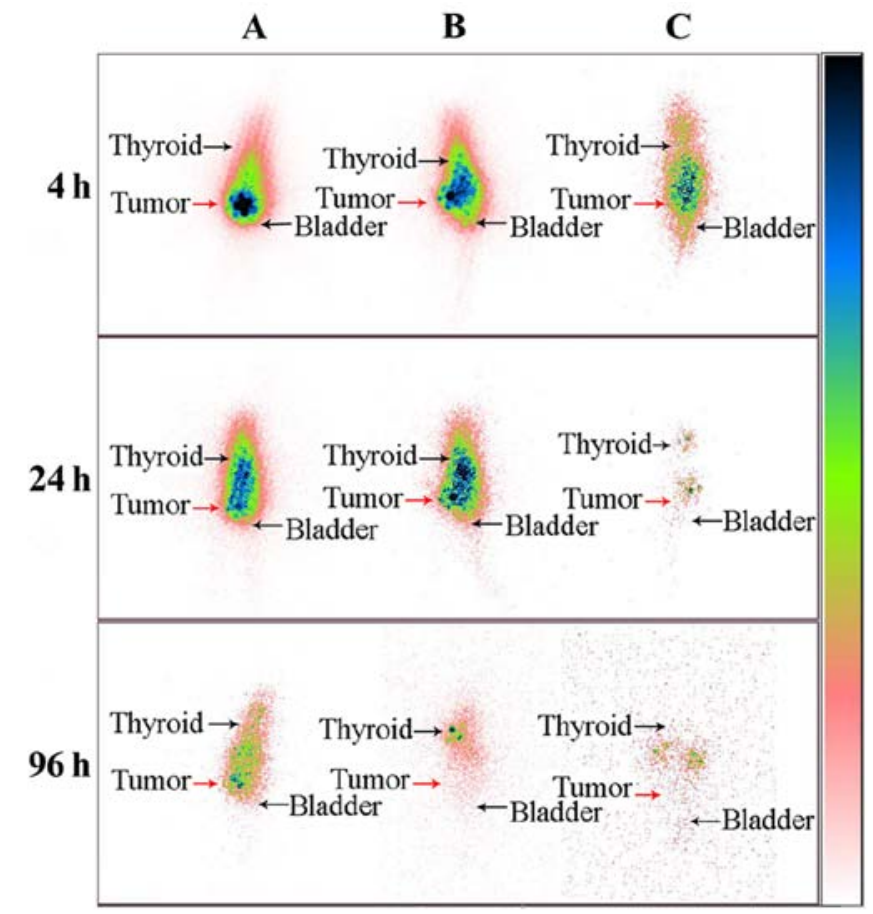

Figure 6. SPECT images after drug administration. (A) ${ }^{131}$ I-EGFR-BSA-PCL; (B) ${ }^{131}$ I-BSA-PCL; (C) ${ }^{131}$ I. SPECT images indicate that after drug administration, development of tumor site was the most clear, and with time, the development of the tumor tissues gradually fade; the other parts of the nude mice developed gradually, indicating that the drug entered through the bloodstream to other parts of the body.

determined by MTT assays as described above. The data showed that both ${ }^{131}$ I-EGFR-BSA-PCL and ${ }^{131}$ I-BSA-PCL could inhibit the growth of U251 and U87 glioma cells. After $4 \mathrm{~h}$ incubation with nanoparticles, the inhibition effect of ${ }^{131}$ I-EGFR-BSA-PCL was better than that of ${ }^{131}$ I-BSA-PCL on tumor cells. The $0.925 \mathrm{MBq}{ }^{131}$ I-EGFR-BSA-PCL or ${ }^{131}$ I-BSA-PCL also had the strongest inhibition effect on tumor cells at $24,48,72$, and $96 \mathrm{~h}$.

In the radioiodine uptake experiments, when the concentration of ${ }^{131}$ I-EGFR-BSA-PCL achieved the maximum lethal dose, further increase of the ${ }^{131}$ I-EGFR-BSA-PCL concentration did not increase the killing effect to the glioma cell. The $0.925 \mathrm{MBq}{ }^{131}$ I-EGFR-BSA-PCL and ${ }^{131}$ I-BSA-PCL had the strongest inhibitory effect on cell growth.

Given that the radiation dose of nanoparticles reached $0.925 \mathrm{MBq}$, the inhibitory effect on tumor cells would decrease as the nanoparticles increased. This finding may be ascribed to the blunt inhibition phenomena, which often occur in the nuclide treatment. A dosage more than the maximum lethal dose of ${ }^{131}$ I-labeled nanoparticles kills the capability of glioma cells to increase; this inhibition usually occurs in thyroid cells (34). Some studies also showed that positive EGFR immunoreactivity predicted poor radiographically assessed radiation response. Significant relationships were noted among the EGFR scores $(35,36)$. Previous studies also suggested that the observed relative radioresistance of some GMs is associated with overexpression of EGFR (36). However, the results cannot explain the weakened inhibition effect of glioma cells when ${ }^{131}$ I-labeled nanoparticles exceed the maximum lethal dose. 
Overall, the results raise the possibility that GBM with EGFR overexpression may derive the most significant benefit, in terms of tumor regression, if treated with ${ }^{131}$ I-EGFRBSA-PCL. This regimen represents new therapeutic and diagnostic approach options for most patients with GBM and provides a foundation for additional studies directed toward further improvement in the outcome of this disease.

In conclusion, the findings of the present study suggested that ${ }^{131}$ I-EGFR-BSA-PCL leading radioiodine therapy for $\mathrm{U} 251$ and $\mathrm{U} 87$ cells had a good effect on in vitro and in vivo experiments. The ${ }^{131} \mathrm{I}$-EGFR-BSA-PCL may provide a new method for glioblastoma treatment.

\section{Acknowledgements}

This study was supported by grants from the National Natural Science Foundation of China (to J.T.) (no. 81171372) (to W.L.) (no. 81301244), the Tianjin Research Program of Application Foundation and Advanced Technology (to J.T.) (no. 12JCZDJC26000), National Key Clinical Speciatly Project of China and the Young incubation funding (TMUGH funding no. 2015040) of Tianjin Medical University General Hospital.

\section{References}

1. Oike T, Suzuki Y, Sugawara K, Shirai K, Noda SE, Tamaki T, Nagaishi M, Yokoo H, Nakazato Y and Nakano T: Radiotherapy plus concomitant adjuvant temozolomide for glioblastoma: Japanese mono-institutional results. PLoS One 8: e78943, 2013.

2. Bouras A, Kaluzova M and Hadjipanayis CG: Radiosensitivity enhancement of radioresistant glioblastoma by epidermal growth factor receptor antibody-conjugated iron-oxide nanoparticles. J Neurooncol 124: 13-22, 2015.

3. Lun X, Wells JC, Grinshtein N, King JC, Hao X, Dang NH, Wang X, Aman A, Uehling D, Datti A, et al: Disulfiram when combined with copper enhances the therapeutic effects of temozolomide for the treatment of glioblastoma. Clin Cancer Res 22: 3860-3875, 2016.

4. Okura H, Smith CA and Rutka JT: Gene therapy for malignant glioma. Mol Cell Ther 2: 21, 2014.

5. Jarzabek MA, Sweeney KJ, Evans RL, Jacobs AH, Stupp R, O'Brien D, Berger MS, Prehn JH and Byrne AT: Molecular imaging in the development of a novel treatment paradigm for glioblastoma (GBM): An integrated multidisciplinary commentary. Drug Discov Today 18: 1052-1066, 2013.

6. Macher-Goeppinger S, Penzel R, Roth W, Dienemann H, Thomas M, Schnabel PA, Schirmacher $\mathrm{P}$ and Bläker $\mathrm{H}$ : Expression and mutation analysis of EGFR, c-KIT, and $\beta$-catenin in pulmonary blastoma. J Clin Pathol 64: 349-353, 2011.

7. Kao H-W, Lin Y-Y, Chen C-C, Chi KH, Tien DC, Hsia CC, Lin MH and Wang HE: Evaluation of EGFR-targeted radioimmuno-gold-nanoparticles as a theranostic agent in a tumor animal model. Bioorg Med Chem Lett 23: 3180-3185, 2013.

8. Tang Y, Wang W, Zheng K, Jiang L, Zou Y, Su X, Chen J, Zhang W and Liu W: EGFR mutations in non-small cell lung cancer: An audit from West China University Hospital. Expert Rev Mol Diagn 16: 915-919, 2016.

9. Brinkman AM, Chen G, Wang Y, Hedman CJ, Sherer NM, Havighurst TC, Gong S and Xu W: Aminoflavone-loaded EGFRtargeted unimolecular micelle nanoparticles exhibit anti-cancer effects in triple negative breast cancer. Biomaterials 101: 20-31, 2016.

10. Chen CL, Hu GY, Mei Q, Qiu H, Long GX and Hu GQ: Epidermal growth factor receptor-targeted ultra-small superparamagnetic iron oxide particles for magnetic resonance molecular imaging of lung cancer cells in vitro. Chin Med J (Engl) 125: 2322-2328, 2012.

11. Chakravarti A, Dicker A and Mehta M: The contribution of epidermal growth factor receptor (EGFR) signaling pathway to radioresistance in human gliomas: A review of preclinical and correlative clinical data. Int J Radiat Oncol Biol Phys 58: 927-931, 2004
12. Bonner JA, Harari PM, Giralt J, Azarnia N, Shin DM, Cohen RB, Jones CU, Sur R, Raben D, Jassem J, et al: Radiotherapy plus cetuximab for squamous-cell carcinoma of the head and neck. N Engl J Med 354: 567-578, 2006.

13. Liu Z, Dong C, Wang X, Wang H, Li W, Tan J and Chang J: Self-assembled biodegradable protein-polymer vesicle as a tumor-targeted nanocarrier. ACS Appl Mater Interfaces 6: 2393-2400, 2014.

14. Su X-Y, Liu P-D, Wu H and Gu N: Enhancement of radiosensitization by metal-based nanoparticles in cancer radiation therapy. Cancer Biol Med 11: 86-91, 2014.

15. Akbari B, Farajnia S, Zarghami N, Mahdieh N, Rahmati M, Khosroshahi SA and Rahbarnia L: Design, expression and evaluation of a novel humanized single chain antibody against epidermal growth factor receptor (EGFR). Protein Expr Purif 127: 8-15, 2016.

16. Liu S, Shi F, Chen L and Su X: Bovine serum albumin coated $\mathrm{CuInS} 2$ quantum dots as a near-infrared fluorescence probe for 2,4,6-trinitrophenol detection. Talanta 116: 870-875, 2013.

17. Behray M, Webster CA, Pereira S, Ghosh P, Krishnamurthy S, Al-Jamal WT and Chao Y: Synthesis of diagnostic silicon nanoparticles for targeted delivery of thiourea to epidermal growth factor receptor-expressing cancer cells. ACS Appl Mater Interfaces 8: 8908-8917, 2016.

18. Sundberg ÅL, Blomquist E, Carlsson J, Steffen A-C and Gedda L: Cellular retention of radioactivity and increased radiation dose. Model experiments with EGF-dextran. Nucl Med Biol 30: 303-315, 2003.

19. Nordberg E, Friedman M, Göstring L, Adams GP, Brismar H, Nilsson FY, Ståhl S, Glimelius B and Carlsson J: Cellular studies of binding, internalization and retention of a radiolabeled EGFRbinding affibody molecule. Nucl Med Biol 34: 609-618, 2007.

20. Sheng R, Luo T, Zhu Y, Li H, Sun J, Chen S, Sun W and Cao A: The intracellular plasmid DNA localization of cationic reducible cholesterol-disulfide lipids. Biomaterials 32: 3507-3519, 2011.

21. Mortensen JH, Jeppesen M, Pilgaard L, Agger R, Duroux M, Zachar V and Moos T: Targeted antiepidermal growth factor receptor (Cetuximab) immunoliposomes enhance cellular uptake in vitro and exhibit increased accumulation in an intracranial model of glioblastoma multiforme. J Drug Deliv 2013: 209205, 2013.

22. Verreault M, Weppler SA, Stegeman A, Warburton C, Strutt D, Masin D and Bally MB: Combined RNAi-mediated suppression of Rictor and EGFR resulted in complete tumor regression in an orthotopic glioblastoma tumor model. PLoS One 8: e59597, 2013.

23. Weiss SJ, Philp NJ and Grollman EF: Iodide transport in a continuous line of cultured cells from rat thyroid. Endocrinology 114: 1090-1098, 1984.

24. Petrich T, Helmeke H-J, Meyer GJ, Knapp WH and Pötter E: Establishment of radioactive astatine and iodine uptake in cancer cell lines expressing the human sodium/iodide symporter. Eur J Nucl Med Mol Imaging 29: 842-854, 2002.

25. Chen J, Wu H, Han D and Xie C: Using anti-VEGF McAb and magnetic nanoparticles as double-targeting vector for the radioimmunotherapy of liver cancer. Cancer Lett 231: 169-175, 2006.

26. Milane L, Duan ZF and Amiji M: Pharmacokinetics and biodistribution of lonidamine/paclitaxel loaded, EGFR-targeted nanoparticles in an orthotopic animal model of multi-drug resistant breast cancer. Nanomedicine (Lond) 7: 435-444, 2011.

27. Dua P and Gude RP: Antiproliferative and antiproteolytic activity of pentoxifylline in cultures of B16F10 melanoma cells. Cancer Chemother Pharmacol 58: 195-202, 2006.

28. Goel PN and Gude RP: Unravelling the antimetastatic potential of pentoxifylline, a methylxanthine derivative in human MDA-MB-231 breast cancer cells. Mol Cell Biochem 358: 141-151, 2011.

29. Jain DS, Athawale RB, Bajaj AN, Shrikhande SS, Goel PN, Nikam Y and Gude RP: Unraveling the cytotoxic potential of Temozolomide loaded into PLGA nanoparticles. Daru 22: 18, 2014.

30. Ohgaki $\mathrm{H}$ and Kleihues P: Genetic pathways to primary and secondary glioblastoma. Am J Pathol 170: 1445-1453, 2007.

31. Nicholas MK, Lukas RV, Jafri NF, Faoro L and Salgia R: Epidermal growth factor receptor - mediated signal transduction in the development and therapy of gliomas. Clin Cancer Res 12: 7261-7270, 2006.

32. Huang PH, Xu AM and White FM: Oncogenic EGFR signaling networks in glioma. Sci Signal 2: re6, 2009. 
33. Herbst RS, Johnson DH, Mininberg E, Carbone DP, Henderson T, Kim ES, Blumenschein G Jr, Lee JJ, Liu DD, Truong MT, et al: Phase I/II trial evaluating the anti-vascular endothelial growth factor monoclonal antibody bevacizumab in combination with the HER-1/epidermal growth factor receptor tyrosine kinase inhibitor erlotinib for patients with recurrent non-small-cell lung cancer. J Clin Oncol 23: 2544-2555, 2005.

34. Schaefers MM, Breshears LM, Anderson MJ, Lin YC, Grill AE, Panyam J, Southern PJ, Schlievert PM and Peterson ML: Epithelial proinflammatory response and curcumin-mediated protection from staphylococcal toxic shock syndrome toxin-1. PLoS One 7: e32813, 2012.
35. Mukohara T, Engelman JA, Hanna NH, Yeap BY, Kobayashi S, Lindeman N, Halmos B, Pearlberg J, Tsuchihashi Z, Cantley LC, et al: Differential effects of gefitinib and cetuximab on nonsmall-cell lung cancers bearing epidermal growth factor receptor mutations. J Natl Cancer Inst 97: 1185-1194, 2005.

36. Barker FG II, Simmons ML, Chang SM, Prados MD, Larson DA, Sneed PK, Wara WM, Berger MS, Chen P, Israel MA, et al: EGFR overexpression and radiation response in glioblastoma multiforme. Int J Radiat Oncol Biol Phys 51: 410-418, 2001. 